\title{
Risk factors for acute kidney injury in critically ill patients receiving high intravenous doses of colistin methanesulfonate and/or other nephrotoxic antibiotics: a retrospective cohort study
}

Monica Rocco ${ }^{1 *}$, Luca Montini², Elisa Alessandri', Mario Venditti ${ }^{3}$, Amalia Laderchi', Gennaro De Pascale ${ }^{2}$, Giammarco Raponi ${ }^{3}$, Michela Vitale ${ }^{1}$, Paolo Pietropaoli ${ }^{1}$ and Massimo Antonelli ${ }^{2}$

\begin{abstract}
Introduction: Use of colistin methanesulfonate (CMS) was abandoned in the 1970s because of excessive nephrotoxicity, but it has been reintroduced as a last-resort treatment for extensively drug-resistant infections caused by gram-negative bacteria (Acinetobacter baumannii, Pseudomonas aeruginosa, Klebsiella pneumonia). We conducted a retrospective cohort study to evaluate risk factors for new-onset acute kidney injury (AKI) in critically ill patients receiving high intravenous doses of colistin methanesulfonate and/or other nephrotoxic antibiotics.

Methods: The cohort consisted of 279 adults admitted to two general ICUs in teaching hospitals between 1 April 2009 and 30 June 2011 with 1) no evidence on admission of acute or chronic kidney disease; and 2) treatment for more than seven days with CMS and/or other nephrotoxic antimicrobials (NAs, that is, aminoglycosides, glycopeptides). Logistic regression analysis was used to identify risk factors associated with this outcome.

Results: The 279 cases that met the inclusion criteria included 147 patients treated with CMS, alone $(n=90)$ or with NAs $(n=57)$, and 132 treated with NAs alone. The 111 (40\%) who developed AKI were significantly older and had significantly higher Simplified Acute Physiology Score II (SAPS II) scores than those who did not develop AKI, but rates of hypertension, diabetes mellitus and congestive heart failure were similar in the two groups. The final logistic regression model showed that in the 147 patients who received CMS alone or with NAs, onset of AKI during the ICU stay was associated with septic shock and with SAPS II scores $\geq 43$. Similar results were obtained in the 222 patients treated with CMS alone or NAs alone.

Conclusions: In severely ill ICU patients without pre-existing renal disease who receive CMS high-dose for more than seven days, CMS therapy does not appear to be a risk factor for this outcome. Instead, the development of AKI was strongly correlated with the presence of septic shock and with the severity of the patients as reflected by the SAPS II score.
\end{abstract}

\footnotetext{
* Correspondence: monica.rocco@uniroma1.it

${ }^{1}$ Anesthesiology and Intensive Care, Sapienza University of Rome, Viale del Policlinico 155, 00161 Rome, Italy

Full list of author information is available at the end of the article
} 


\section{Introduction}

Throughout the world, Acinetobacter baumannii, Pseudomonas aeruginosa and Klebsiella pneumonia have emerged as major causes of nosocomial infections [1], particularly in patients who are critically ill and/or immunocompromised. Concern has been raised by reports of a stepwise trend towards extensive drug-resistance in these organisms [1]. Infections caused by extensively drug-resistant (XDR) bacterial strains are associated with high mortality rates, especially in intensive care units (ICUs), where outbreaks are extremely difficult to control. The limited therapeutic options in these cases often lead clinicians to resort to salvage therapy with colistin methanesulfonate (CMS). This older polymyxin antibiotic, which is converted in vivo to colistin [2], was widely abandoned in the 1970s because of its unfavorable pharmacokinetic properties and frequent adverse effects, particularly nephrotoxicity.

The "modern polymyxin era" [3], which began in the late 1990s, is characterized by a variety of dosing schedules, but to date there is still a dearth of information on the clinical pharmacokinetics of CMS and colistin in critically ill patients [4]. Higher doses appear to be beneficial in these cases [5], but it is unclear whether the improved efficacy comes at a cost of increased toxicity. The aim of this retrospective cohort study was to evaluate the potential risk factors for acute kidney injury (AKI), as defined by the RIFLE (Risk of renal dysfunction, Injury to the kidney, Failure of kidney function, Loss of kidney function, End-stage kidney disease) classification system [6], in severely ill ICU patients without pre-existing renal disease who received high-dose intravenous CMS therapy for more than seven days.

\section{Materials and methods}

This study was conducted in two large tertiary-care teaching hospitals in Rome, Italy (Policlinico Umberto I and the Policlinico Gemelli), and it involved retrospective analysis of prospectively collected data. Cases were identified through searches of the ICU patient databases, and data were collected from the patients' electronic medical records.

The study cohort consisted of adults ( $\geq 18$ years) consecutively admitted to the general ICUs of the participating facilities between April 2009 and June 2011 (Figure 1). Inclusion criteria were: 1) no evidence on ICU admission - as well as at protocol admission - of chronic renal failure and normal estimated glomerular

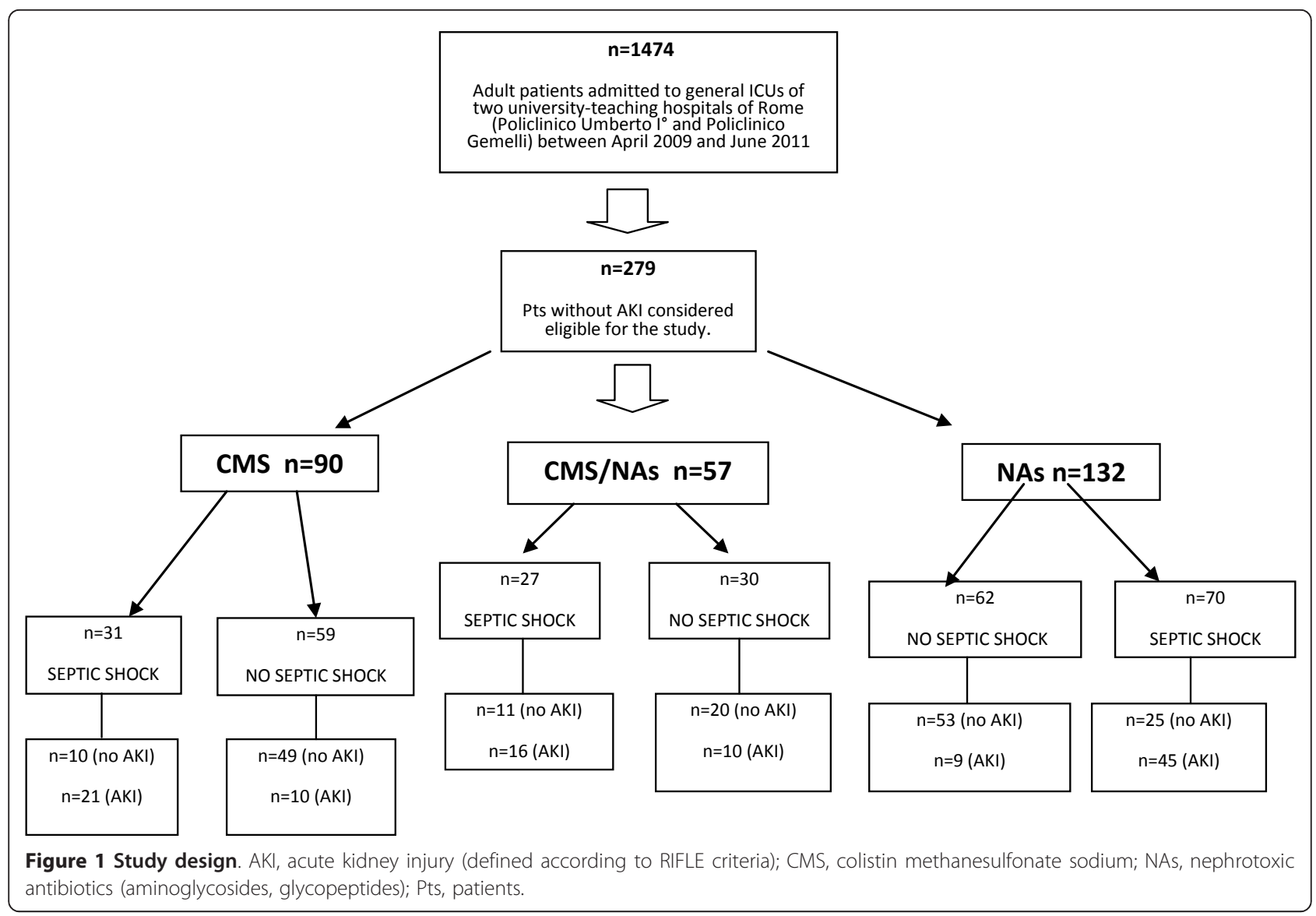


filtration rate (GFR) relative to serum creatinine (SCr) based on age, race and sex formula assuming a glomerular filtration rate of $75 \mathrm{~mL} / \mathrm{min} / 1.73 \mathrm{~m}^{2}$, as recommended by the Acute Dialysis Quality Initiative (ADQI) Working Group [6]. Most ICU patients, in fact, have not a prior measure of renal function and a simplified modification of diet in renal disease (MDRD) formula provides a simple and precise estimation of baseline GFR and $\mathrm{SCr}$ 2) onset $\geq 48 \mathrm{~h}$ after ICU admission of an XDR bacterial infection treated for seven or more days with intravenous (iv) CMS and/or other nephrotoxic antimicrobial agents (NAs, that is, aminoglycosides and glycopeptides).

Extensively drug-resistant (XDR) was defined as nonsusceptibility to at least one agent in all but two or fewer antimicrobial categories (that is, bacterial isolates remain susceptible to only one or two categories) [7]. Patients were excluded if the antibiotic therapy described above had been started prior to ICU admission.

The primary end point of the study was to evaluate the potential risk factors for acute kidney injury (AKI) in severely ill ICU patients without pre-existing renal disease who received high-dose intravenous CMS therapy with or without other nephrotoxic antimicrobials.

For this purpose, patients were classified daily using the RIFLE criteria and AKI was defined using the serum creatinine compared to the baseline value of the $\mathrm{SCr}$ previously obtained from the MDRD equation.

A patient was considered to have AKI when he had an increase in $\mathrm{SCr}$ of at least $50 \%$ from baseline (defined as Risk) or if he doubled the $\mathrm{SCr}$ level from the baseline (defined as Injury) or had a three times increase in $\mathrm{SCr}$ (defined as Failure) [6,8] (Figure 2).

For each patient included in the cohort, electronic hospital charts were reviewed, and the following collected data were recorded: demographic variables; Simplified
Acute Physiology Score II (SAPS II); presence on admission of hypertension, diabetes mellitus, and/or congestive heart failure; reason for ICU admission; length of ICU stay; type and cause of infection; nephrotoxic drugs and iv iodate contrast used, immunocompromised status; albumin serum level, bilirubin serum level and, for CMS, duration of therapy and cumulative doses; presence of septic shock caused by the XDR infection; use of continuous renal replacement therapy (CRRT) during the ICU stay and ICU mortality.

Septic shock was diagnosed as a state of acute circulatory failure characterized by persistent arterial hypotension despite adequate fluid resuscitation or by tissue hypoperfusion in the presence of proven or suspected infection [9]. Bloodstream infection (BSI) was defined as at least one positive blood culture for a potential bacterium together with clinical features compatible with systemic inflammatory response syndrome; the clinical suspicion of pneumonia was based on either clinical criteria (new or progressive radiologic pulmonary infiltrate together with at least two of the following: temperature $>38^{\circ} \mathrm{C}$ or $<36^{\circ} \mathrm{C}$, leukocytosis $>12,000 / \mathrm{mL}$ or leucopoenia $<4,000 / \mathrm{mL}$, or purulent respiratory secretions) or a simplified Clinical Pulmonary Infectious Score greater than or equal to six points. The microbiologic evaluation included the collection of at least one lower respiratory airway sample by tracheobronchial aspirates, bronchoscopic or blind bronchoalveolar lavage, within the first 24 hours of the onset of symptoms. Microbiologic confirmation of pneumonia was defined by the presence of at least one potentially pathogenic microorganism in respiratory samples above predefined thresholds bronchoalveolar lavage $>10^{4}$, and sputum or tracheobronchial aspirates $>10^{5}$ colony-forming units $/ \mathrm{ml}$, respectively $[10,11]$

\begin{tabular}{|c|c|c|}
\hline CLASS & GFR CRITERIA & URINARY OUTPUT CRITERIA \\
\hline RISK & Serum creatinine $\times 1.5$ or GFR decrease $>25 \%$ & $<0.5 \mathrm{ml} / \mathrm{kg} / \mathrm{h} \times 6 \mathrm{~h}$ \\
\hline INJURY & Serum creatinine $\times 2$ or GFR decrease $>50 \%$ & $<0.5 \mathrm{ml} / \mathrm{kg} / \mathrm{h} \times 12 \mathrm{~h}$ \\
\hline FAILURE & $\begin{array}{l}\text { Serum creatinine } \times 3 \text {, or GFR decrease }>75 \% \\
\text { Serum creatinine } \geq 4 \mathrm{mg} / \mathrm{d} \text { with an acute rise }>0.5 \mathrm{mg} / \mathrm{dl}\end{array}$ & $<0.3 \mathrm{ml} / \mathrm{kg} / \mathrm{h} \times 24 \mathrm{~h}$, or anuria $12 \mathrm{~h}$ \\
\hline $\begin{array}{l}\text { LOSS } \\
\text { END-STAGE } \\
\text { KIDNEY DISEASE }\end{array}$ & \multicolumn{2}{|c|}{$\begin{array}{l}\text { Persistent acute renal failure }=\text { complete loss of kidney function }>4 \text { weeks } \\
\text { End-stage kidney disease }>3 \text { months }\end{array}$} \\
\hline \multicolumn{3}{|c|}{$\begin{array}{l}\text { Figure } 2 \text { RIFLE classification. Patients are classified on serum creatinine or urinary output, or both, the worst parameters are used. Glomerular } \\
\text { filtration rate (GFR) criteria are calculated as an increase of serum creatinine above the baseline serum creatinine level. When the baseline serum } \\
\text { creatinine is unknown and there is no past history of chronic kidney disease, serum creatinine is calculated using the Modification of Diet in Renal } \\
\text { Disease formula for assessment of kidney function assuming a GFR of } 75 \mathrm{ml} / \mathrm{min} / 1.73 \mathrm{~m}^{2} \text {. RIFLE, Risk Injury-Failure-Loss-End-stage kidney disease. }\end{array}$} \\
\hline
\end{tabular}


This study was approved by our institutional review board that waived the need for informed consent, due to the retrospective design of this study.

\section{Statistical analysis}

MedCalc software, version 12.1.0 (MedCalc ${ }^{\circledR}$ Software v 12.2.1, MariaKerke, Belgium) was used for all statistical analyses. Differences between groups were assessed with the Mann-Whitney test and results given as medians and interquartile ranges (IQR). The Kolmogorov-Smirnov test was used to assess variable distribution. Categorical variables, presented as proportions, were analyzed with the chi-square test or Fisher's exact test, as appropriate. $P$-values of $<0.05$ were regarded as significant. Potential risk factors for AKI were identified by means of univariate analysis with calculation of crude odds ratios (ORs). Those that emerged from this analysis with a $P$-value of $<0.2$ were candidates for inclusion in the multivariate model. The variables included in the final predictive model were selected with a stepwise procedure, and the accuracy of the model was assessed in terms of the area under the receiver operating characteristic (ROC) curve.

\section{Results}

Between April 2009 and June 2011, 1,474 adult patients were consecutively admitted to the two participating ICUs, and 279 (19\%) of these met the criteria for inclusion in the study (Figure 1). Their characteristics are reported in Tables 1 and 2. The NAs patients were older, had a longer ICU stay and had a higher percentage immunocompromised than the other groups; the number of NAs patients treated with nonsteroidal antiinflammatory drugs (NSAIDs) were statistically significant in respect to the CMS group (Table 1).

One hundred thirty-two of the patients received intravenous therapy with NAs alone (glycopeptides and aminoglycosides). Eight (6\%) of these patients received two nephrotoxic antimicrobials.

The other 147 were treated intravenously with CMS, alone (CMS group, $\mathrm{n}=90$ ) or with one or more NAs (CMS + NAs group, $\mathrm{n}=57)$. The NAs in the latter group were vancomycin in 39 cases, vancomycin plus amikacin in 7 , amikacin in 5 , gentamicin in 3 , and vancomycin plus gentamicin in 3 . In all cases, the infection was associated with at least one bacterial isolate that displayed persistent in vitro susceptibility to colistin only. In the subgroup that was also receiving NAs, patients also had one or more isolates displaying susceptibility to the specific NA being administered.

CMS was administered as Colimicina ${ }^{\circledR}$ (UCB Pharma SpA, Milan, Italy); 1 million UI per vial). All 147 patients received a loading dose of CMS (4 million IU) followed by a daily dose of 130,000 IU per kilogram of ideal body weight (IBW) (divided into three doses per day) [12]. For patients with creatinine clearance of less than $70 \mathrm{~mL} / \mathrm{min}$ but more than $30 \mathrm{~mL} / \mathrm{min}$ one-third of the normal daily dose twice a day (for example, 6 million IU divided into two doses per day for a $70 \mathrm{Kg}$ patient); with a creatinine clearance $<30 \mathrm{~mL} / \mathrm{min}$ onethird of the normal daily dose once a day (for example, 3 million IU once a day for a $70 \mathrm{Kg}$ patient); during CRRT we used one-third of the normal daily dose twice a day $[13,14]$.

The median length of CMS therapy was 11 days; the cumulative CMS dose was 93.999.975 IU, and there were no significant differences between the CMS and CMS + NA subgroups involving any of these variables ( $P=0.26$ and $P=0.37$, respectively)

Normogram based on creatinine clearance (CLCr) was used for calculation of the vancomycin daily dosage administered by continuous infusion in order to target a steady state concentration (CSS) at 15 to $20 \mathrm{mg} / \mathrm{L} \mathrm{[15].}$ We, therefore, confirm our dosage monitoring the serum vancomicin concentration. Aminoglycoside were administered according to one daily dosing schedule of $20 \mathrm{mg} / \mathrm{kg} /$ day for Amikacin and $5 \mathrm{mg} / \mathrm{kg} /$ day for Gentamycin; dosage was confirmed by monitoring the serum concentration and was adjusted as a function of CLCr. The target trough $(1 \mu \mathrm{g} / \mathrm{mL})$ was easily achieved using a once daily dose [16]

A total of $116(41 \%)$ of the patients died while they were in ICU (Table 1).

One hundred eleven (40\%) of the 279 patients developed AKI during their stay in the ICU. In the NAs group, $10 \%$ the AKI cases were classified as Risk, $13 \%$ as Injury and $18 \%$ as Failure; in the CMS group, $6 \%$ of the cases were classified as Risk, $7 \%$ as Injury and $22 \%$ as Failure; and in the CMS + NAs group, 7\% of the AKI cases classified as Risk, $12 \%$ as Injury and $26 \%$ as Failure. The median onset of AKI was 10 days ( 8 to 15$)\left(25^{\text {th }}\right.$ to $\left.75^{\text {th }}\right)$ in the CMS group, 11 days (10 to 12$)\left(25^{\text {th }}\right.$ to $\left.75^{\text {th }}\right)$ in the NAs group, 12 days (10 to 21$)\left(25^{\text {th }}\right.$ to $\left.75^{\text {th }}\right)$ in the CMS + NAs group. Compared with the non-AKI subgroup, those who developed AKI were significantly older and had significantly higher SAPS II scores. In addition, septic shock rates and ICU mortality were roughly three times higher than those in the non-AKI group; in fact, in the AKI group, the ICU mortality and septic shock rates were $70 \%$ and $74 \%$, respectively (Table 2 ). The vast majority of AKI patients had an albumin serum level less than $2 \mathrm{~g} / \mathrm{dL}$ (Table 2). The vast majority of the infections considered in this study were ventilator-associated pneumonia (VAP) or catheter-related bloodstream infections (CRBSIs), and in almost half of all cases (46\%), septic shock was present at infection onset.

We did not find any difference in the incidence of AKI in respect to the etiology of infections among the 
Table 1 ACEI, angiotensin converter enzyme inhibitor; AKI, acute kidney injury as defined per RIFLE criteria; BMI, body mass index; BSI, bloodstream infection; CMS, colistin methanesulfonate sodium; CRRT, continuous renal replacement therapy; CVC, central venous catheter; NSAID, nonsteroidal anti-inflammatory drug; Pts, patients; SAPS II, simplified acute physiology score two (calculated $24 \mathrm{~h}$ after ICU admission); VAP, ventilator-associated pneumonia.

\begin{tabular}{|c|c|c|c|}
\hline VARIABLES & $\begin{array}{c}\text { CMS } \\
(\mathrm{n}=90)\end{array}$ & $\begin{array}{c}\text { CMS + NAs } \\
(\mathrm{n}=57)\end{array}$ & $\begin{array}{c}\text { NAs } \\
(n=132)\end{array}$ \\
\hline Age (years) & $57(40$ to 69$)$ & 54 (39 to 66$)$ & $67(48 \text { to } 76)^{*}$ \\
\hline Female, n (\%) & $32(35)$ & $20(35)$ & $40(30)$ \\
\hline SAPS $\|$ & 41 (32 to 54 ) & 44 (30 to 54$)$ & 44 (35 to 55$)$ \\
\hline $\mathrm{BMI}, \mathrm{Kg} / \mathrm{m}^{2}$ & 25 (24 to 25$)$ & 24 (23.7 to 25$)$ & 24 (23 to 27$)$ \\
\hline ICU length of stay, (days) & 28 (17 to 38$)$ & $33(19$ to 50$)$ & $15(8$ to 31$) *$ \\
\hline Albumin serum level <2 g/dL, n (\%) & $14(15)$ & $9(16)$ & $18(14)$ \\
\hline Total bilirubin serum level >5 mg/dL n (\%) & $7(8)$ & $4(7)$ & $11(8)$ \\
\hline NSAID n (\%) & $17(19)$ & $10(18)$ & $43(33) * * * *$ \\
\hline ACEI n (\%) & $15(17)$ & $3(5)$ & $16(12)$ \\
\hline i.v. iodate contrast n (\%) & $35(39)$ & $14(25)$ & $45(34)$ \\
\hline Immunocompromised pts n (\%) & $13(14)$ & $8(14) * * *$ & $38(29) * *$ \\
\hline \multicolumn{4}{|l|}{ Reason for ICU admission } \\
\hline Sepsis, n (\%) & $41(46)$ & $20(35)$ & $56(43)$ \\
\hline Neurological injury, n (\%) & $4(4)$ & $8(14)$ & $12(9)$ \\
\hline Traumatic injury, n (\%) & $31(34)$ & $21(37)$ & $31(23)$ \\
\hline Cardiovascular injury, n (\%) & $14(16)$ & $8(14)$ & $33(25)$ \\
\hline \multicolumn{4}{|l|}{ Comorbidity } \\
\hline Hypertension, n (\%) & $14(16)$ & $12(21)$ & $28(21)$ \\
\hline Diabetes mellitus, n (\%) & $2(2)$ & $2(3.5)$ & $9(7)$ \\
\hline Congestive heart failure, $\mathrm{n}(\%)$ & $3(3)$ & $2(3.5)$ & $10(7.5)$ \\
\hline Two or more comorbidities, n (\%) & $5(5)$ & $4(7)$ & $16(12)$ \\
\hline \multicolumn{4}{|l|}{ Site of infection } \\
\hline VAP, n (\%) & $69(77)$ & $40(70)$ & $91(69)$ \\
\hline CVC related-BSI, n (\%) & $18(20)$ & $13(23)$ & $31(23)$ \\
\hline Other, n (\%) & $3^{\mathrm{a}}(3)$ & $4^{\mathrm{b}}(7)$ & $10^{c}(7)$ \\
\hline \multicolumn{4}{|l|}{ Complications occurring during ICU stay } \\
\hline CRRT, n (\%) & $13(14)$ & $14(24)$ & $29(22)$ \\
\hline AKI, n (\%) & $31(34)$ & $26(45)$ & $54(41)$ \\
\hline Septic shock, n (\%) & $31(34)$ & $27(47)$ & $70(53)$ \\
\hline ICU mortality, n (\%) & $31(34)$ & $21(37)$ & $64(49)$ \\
\hline
\end{tabular}

Other nephrotoxic antimicrobial included aminoglycosides and glycopeptides.

(a) wound infection $n=2$, abdominal abscess $n=1$. ${ }^{\text {(b) }}$ wound infection $n=1$, abdominal abscess $n=1$, urinary tract infection $n=2$. (c) urinary infection $n=4$, abdominal abscess $n=3$, wound infection $n=1$, meningitis $n=2$. Values are given as the median (interquartile range).

${ }^{*} P<0.01 \mathrm{NAs}$ vs CMS and CMS/NAs; ${ }^{* *} P=0.01 \mathrm{CMS}$ vs NAs; ${ }^{* * *} P=0.04 \mathrm{CMS} / \mathrm{NAs}$ vs NAs $P=0.03 * * * *$

three groups studied. Nine out of 17 Failure patients who survived were discharged from ICU as Failure but without a dialysis prescription; 1 as Injury, 4 as Risk and 3 with a complete recovery of the renal function. Five out of 7 Injury patients who survived were discharged from ICU as Injury and 2 as Risk. Five out of 9 Risk patients who survived were discharged from ICU as Risk and 4 with a complete recovery of the renal function (Table 3).

The results of the logistic regression are shown in Tables 3, 4 and 5. In the complete study population $(\mathrm{n}=$ 279), the multivariate analysis showed that SAPS II scores and the presence of septic shock at infection onset were independently associated with AKI. The other significant variables at the univariate analysis were not included in the multivariate final logistic model using a stepwise procedure. A ROC curve analysis was performed to assess the accuracy of the final regression model showing $\mathrm{AUC} \pm \mathrm{SE}=0.79 \pm 0.03$ with $95 \%$ C.I. 0.74 to 0.84 ; Chi Square statistics: $P<0.001$ (Table 4). In the 147 patients who received CMS (Table 5), the likelihood of developing AKI was not significantly different in the CMS and CMS + NA subgroups. In contrast, onset of AKI was two times more likely in patients with a SAPS II score $\geq 43$ and six times more likely in those whose infections had presented with septic shock. A ROC curve 
Table 2 ACEI, angiotensin converter enzyme inhibitor; AKI, acute kidney injury; BSI, bloodstream infection; CMS, colistin methanesulfate; CVC, central venous catheter; NAs, other nephrotoxic antibiotics (aminoglycosides, glycopeptides); NSAID, nonsteroidal anti-inflammatory drug; SAPS II, Simplified Acute Physiology Score Two (calculated $24 \mathrm{~h}$ after ICU admission); VAP, ventilator-associated pneumonia.

\begin{tabular}{|c|c|c|c|c|}
\hline Variables & $\begin{array}{l}\text { Total cohort } \\
(\mathrm{n}=79)\end{array}$ & $\begin{array}{c}\text { No AKI } \\
(n=168)\end{array}$ & $\begin{array}{c}\text { AKI } \\
(n=111)\end{array}$ & $P$-value a \\
\hline Age, years ${ }^{b}$ & $61(43$ to 74$)$ & 58 (39 to 71$)$ & 66 (51 to 77$)$ & $<0.01 *$ \\
\hline Female, n (\%) & $92(33)$ & $62(37)$ & $30(27)$ & $0.09^{* *}$ \\
\hline SAPS $\|$ score $^{b}$ & 44 (32 to 54$)$ & 38 (29 to 49$)$ & 50 (41 to 56$)$ & $<0.01 *$ \\
\hline Septic shock at infection onset - n (\%) & $128(46)$ & $46(27)$ & $82(74)$ & $<0.01 * *$ \\
\hline Albumin serum levels <2 g/dL n (\%) & $38(14)$ & $15(9)$ & $23(21)$ & $<0.01 * *$ \\
\hline Total bilirubin serum levels $>5$ mg/dL n(\%) & $19(7)$ & $8(5)$ & $11(10)$ & $0.15^{* *}$ \\
\hline NSAID n (\%) & $70(25)$ & $48(28)$ & $22(20)$ & $0.13 * *$ \\
\hline ACEI n (\%) & $34(12)$ & $16(10)$ & $18(16)$ & $0.13 * *$ \\
\hline Immunocompromised pts n (\%) & $59(21)$ & $34(20)$ & $25(23)$ & $0.75 * *$ \\
\hline i.v. iodate contrast n (\%) & $94(34)$ & $53(32)$ & $41(37)$ & $0.42 * *$ \\
\hline \multicolumn{5}{|l|}{ Reason for ICU admission } \\
\hline Sepsis, n (\%) & $117(42)$ & $60(36)$ & $57(51)$ & $0.01 * *$ \\
\hline Neurological disease, n (\%) & $24(8)$ & $18(10)$ & $6(5)$ & $0.18^{* *}$ \\
\hline Trauma, n (\%) & $83(30)$ & $62(37)$ & $21(19)$ & $<0.01 * *$ \\
\hline Cardiovascular disease, n (\%) & $55(20)$ & $28(17)$ & $27(24)$ & $0.15^{* *}$ \\
\hline \multicolumn{5}{|l|}{ Comorbidity } \\
\hline Hypertension, n (\%) & $54(20)$ & $27(16)$ & $27(24)$ & $0.12^{* *}$ \\
\hline Diabetes mellitus, (\%) & $13(4)$ & $6(4)$ & $7(6)$ & $0.44^{* *}$ \\
\hline Congestive heart failure, n (\%) & $15(6)$ & $9(5)$ & $6(5)$ & $0.79 * *$ \\
\hline Two or more comorbidities & $25(9)$ & $11(6)$ & $14(13)$ & $0.13 * *$ \\
\hline \multicolumn{5}{|l|}{ Type of infection } \\
\hline VAP, n (\%) & $200(72)$ & $118(70)$ & $82(74)$ & $0.6^{* *}$ \\
\hline CVC related-BSI, n (\%) & $62(23)$ & $39(23)$ & $23(21)$ & $0.73 * *$ \\
\hline Other, n (\%) & $17(5)$ & $11(7)^{c}$ & $6(5)^{d}$ & $0.89 * *$ \\
\hline \multicolumn{5}{|l|}{ Treatment } \\
\hline CMS, n (\%) & $90(32)$ & $59(35)$ & $31(28)$ & $0.25^{* *}$ \\
\hline CMS+NAs, n (\%) & $57(20)$ & $31(18)$ & $26(23)$ & $0.39 * *$ \\
\hline CMS+ glycopeptides alone ${ }^{\mathrm{e}}, \mathrm{n}(\%)$ & $39(68)$ & $23(59)$ & $16(41)$ & $1^{* * *}$ \\
\hline CMS + aminoglicoside alone ${ }^{e}, \mathrm{n}(\%)$ & $8(14)$ & $5(62.5)$ & $3(37.5)$ & \\
\hline NAs, n (\%) & $132(47)$ & $78(47)$ & $54(48)$ & $0.8 * *$ \\
\hline \multicolumn{5}{|l|}{ Outcome } \\
\hline Days in ICU ${ }^{b}$ & 23 (13 to 37$)$ & 22 (13 to 34$)$ & 25 (14 to 42$)$ & $0.16 *$ \\
\hline ICU mortality - n (\%) & $116(41)$ & $38(23)$ & $78(70)$ & $<0.01 * *$ \\
\hline
\end{tabular}

${ }^{a}$ Differences between subgroups with and without AKI onset after ICU admission: *Mann-Whitney test; ${ }^{* *}$ Chi-squared test, ${ }^{* * *}$ Fisher's exact test

${ }^{b}$ Values are given as the median (interquartile range).

c wound infection $n=2$, abdominal abscess $n=5$, urinary tract infection $n=2$, meningitis $n=2$

${ }^{d}$ wound infection $n=1$, abdominal abscess $n=3$, urinary tract infection $n=2$

${ }^{e}$ in this analysis were excluded the patients who received aminoglycoside + glycopeptide $(n=10)(18 \%)$

Table 3 Outcome at the ICU discharge of AKI patients

\begin{tabular}{llllll}
\hline $\begin{array}{l}\text { AKI during ICU } \\
\text { stay }\end{array}$ & \multicolumn{6}{l}{ Outcome at ICU discharge } \\
\hline & $\begin{array}{l}\text { Normal } \\
(\mathbf{n})\end{array}$ & $\begin{array}{l}\text { Risk } \\
(\mathbf{n})\end{array}$ & $\begin{array}{l}\text { Injury } \\
(\mathbf{n})\end{array}$ & $\begin{array}{l}\text { Failure } \\
(\mathbf{n})\end{array}$ & $\begin{array}{l}\text { Dead } \\
(\mathbf{n})\end{array}$ \\
\hline Risk $\mathrm{n}=22$ & 4 & 5 & 0 & 0 & 12 \\
Injury $\mathrm{n}=30$ & 0 & 2 & 5 & 0 & 21 \\
Failure $\mathrm{n}=59$ & 3 & 4 & 1 & 9 & 45 \\
\hline
\end{tabular}

analysis was performed to assess the accuracy of the final regression model showing $\mathrm{AUC} \pm \mathrm{SE}=0.76 \pm 0.04$ with 95\% CI 0.7 to 0.8; Chi-square statistics $P<0.001$.

A similar picture emerged when we analyzed the 222 patients who received CMS alone $(n=90)$ or NAs alone $(\mathrm{n}=132)$ (Table 6). The only independent predictors of AKI in this group were SAPS II scores $\geq 44$ and septic shock at infection onset. A ROC curve analysis was 
Table 4 Logistic regression analysis of factor associated with AKI in the study cohort

\begin{tabular}{|c|c|c|c|c|c|c|}
\hline \multirow[b]{2}{*}{ Variables } & \multicolumn{3}{|c|}{ Univariate analysis } & \multicolumn{3}{|c|}{ Multivariate analysis } \\
\hline & O.R. & 95\% C.I. & $P$-value & O.R. & 95\% C.I. & $P$-value \\
\hline Age, years & 1.02 & 1.01 to 1.04 & $<0.01$ & & & \\
\hline SAPS II score & 1.04 & 1.03 to 1.06 & $<0.01$ & 1.03 & 1.01 to 1.05 & $<0.01$ \\
\hline Female & 0.63 & 0.37 to 1.06 & 0.08 & 0.62 & 0.34 to 1.14 & 0.12 \\
\hline Septic shock at infection onset & 7.5 & 4.36 to 12.9 & $<0.01$ & 5.89 & 3.35 to 10.35 & $<0.01$ \\
\hline Albumin serum levels $<2 \mathrm{~g} / \mathrm{dL}$ & 2.66 & 1.32 to 5.37 & $<0.01$ & & & \\
\hline Total bilirubin serum levels $>5 \mathrm{mg} / \mathrm{dL}$ & 2.2 & 0.85 to 5.65 & 0.1 & & & \\
\hline NSAID & 0.62 & 0.35 to 1.1 & 0.1 & & & \\
\hline ACEl & 1.83 & 0.89 to 3.78 & 0.1 & & & \\
\hline i.v. iodate contrast & 1.27 & 0.76 to 2.1 & 0.35 & & & \\
\hline Immunocompromised status & 1.14 & 0.63 to 2.05 & 0.64 & & & \\
\hline \multicolumn{7}{|l|}{ Causes of ICU admission } \\
\hline Sepsis & 1.9 & 1.17 to 3.1 & $<0.01$ & 1.74 & $0.99-3.05$ & 0.052 \\
\hline Neurological disease & 0.47 & 0.18 to 1.24 & 0.13 & & & \\
\hline Trauma & 0.4 & 0.22 to 0.7 & $<0.01$ & & & \\
\hline Cardiovascular disease & 1.61 & 0.89 to 2.9 & 0.12 & & & \\
\hline \multicolumn{7}{|l|}{ Co-morbidities } \\
\hline Hypertension & 1.68 & 0.92 to 3.05 & 0.09 & & & \\
\hline Diabetes mellitus & 1.79 & 0.58 to 5.47 & 0.31 & & & \\
\hline Congestive heart failure & 1 & 0.35 to 2.92 & 0.99 & & & \\
\hline Two or more comorbidities & 2.06 & 0.9 to 4.72 & 0.08 & & & \\
\hline \multicolumn{7}{|l|}{ Type of infection } \\
\hline VAP & 1.19 & 0.7 to 2.05 & 0.51 & & & \\
\hline CVC related-BSI & 0.86 & 0.48 to 1.55 & 0.62 & & & \\
\hline Other & 0.81 & 0.29 to 2.27 & 0.7 & & & \\
\hline Treatment with CMS (vs. NAs) & 0.91 & 0.56 to 1.47 & 0.7 & & & \\
\hline
\end{tabular}

The variables included in the final predictive model were selected with a stepwise procedure: albumin serum levels $<2 \mathrm{~g} / \mathrm{dL}$, total bilirubin serum levels $>5 \mathrm{mg} /$ $\mathrm{dL}$, ACE inhibitors, NSAID, age, neurological disease, trauma, cardiovascular disease, hypertension and two or more co-morbidities were variables not included in the final model. We assessed discrimination of the model with area under the receiver operating curve (AUC \pm SE $=0.79 \pm 0.03$ with $95 \%$ C.I. 0.74 to 0.84 ; Chi Square statistics: $P<0.001$.

ACEl, angiotensin converter enzyme inhibitor; AUC, area under the curve; BSI, bloodstream infection; Cl, confidence interval; CMS, colistin methanesulfate; CVC, central venous catheter; NAs, other nephrotoxic antibiotics (aminoglycosides, glycopeptides); NSAID, nonsteroidal anti-inflammatory drug; SAPS II, Simplified Acute Physiology Score Two (calculated $24 \mathrm{~h}$ after ICU admission); VAP, ventilator-associated pneumonia.

performed to assess the accuracy of the final regression model showing AUC $=0.8 \pm 0.03$ with 0.75 to $0.8695 \%$ CI; Chi-square statistics: $P<0.01$.

These findings indicate that in ICU patients without pre-existing renal disease who require nephrotoxic antimicrobial drug therapy for XDR bacterial infections, the use of CMS - with or without NAs - does not significantly increase the risk for AKI over that associated with NAs therapy alone.

\section{Discussion}

The cohort treated with high doses of CMS for nosocomial XDR infections in our study represented approximately $10 \%$ of the entire population admitted to the general ICUs during the two-year study period. The overall incidence of AKI in the 279 cases we analyzed was $40 \%$, and there were no significant differences among rates observed in the CMS (34\%), CMS+NAs $(45 \%)$ and NAs subgroups $(41 \%)$. These data are consistent with the results of the Nefroint study [8], a multicenter study conducted in Italian ICUs: in the subgroup of 133 patients without AKI at ICU admission, the incidence of AKI was $40 \%$ regardless of whether or not nephrotoxic drugs were administered. A recent meta-analysis [17] on six controlled studies comparing colistin vs other antibiotics for treatment of VAP in patients without cystic fibrosis suggested that colistin may be as safe as other standard antibiotics used for these drug-resistant infections. In particular, the nephrotoxicity rate for colistin was similar to that in the control group.

Our multivariate analysis revealed that SAPS II scores $\geq 43$ and the presence of septic shock at infection onset were independently associated with AKI, but high-dose intravenous CMS therapy for more than seven days was not a risk factor for development of new onset AKI.

Since CMS's recent re-emergence as a last-resort treatment of infections caused by XDR pathogens 
Table 5 Logistic regression analysis of factors associated with AKI in patients who received CMS and CMS/NAs.

\begin{tabular}{|c|c|c|c|c|c|c|c|}
\hline \multirow[b]{2}{*}{ Variables } & \multirow[b]{2}{*}{ No. AKI/total (\%) } & \multicolumn{3}{|c|}{ Univariate analysis } & \multicolumn{3}{|c|}{ Multivariate analysis $^{\mathbf{b}}$} \\
\hline & & O.R. & 95\% C.I. & $P$-value & O.R. & 95\% C.I. & $P$-value \\
\hline \multicolumn{8}{|c|}{ Age, years ${ }^{a}$} \\
\hline$<55$ & 23/71 (32) & 1.00 & & & & & \\
\hline$\geq 55$ & $34 / 76(45)$ & 1.68 & $0.86-3.31$ & 0.13 & & & \\
\hline \multicolumn{8}{|c|}{ Sex } \\
\hline Male & 39/95 (41) & 1.00 & & & & & \\
\hline Female & 18/52 (34) & 0.76 & $0.37-1.53$ & 0.44 & & & \\
\hline \multicolumn{8}{|c|}{ SAPS $\|^{a}$} \\
\hline$<43$ & 20/73 (27) & 1.00 & & & & & \\
\hline$\geq 43$ & $37 / 74(50)$ & 2.65 & $1.33-5.27$ & $<0.01$ & 2.26 & $1.07-4.79$ & 0.03 \\
\hline \multicolumn{8}{|c|}{ Septic shock at Infection onset } \\
\hline No & 20/89 (22) & 1.00 & & & & & \\
\hline Yes & $37 / 58(64)$ & 6.1 & $2.92-12.62$ & $<0.01$ & 5.64 & $2.66-11.94$ & $<0.01$ \\
\hline \multicolumn{8}{|c|}{ Treatment with CMS } \\
\hline CMS with NAs & $26 / 57(45)$ & 1.00 & & & & & \\
\hline CMS alone & $31 / 90(34)$ & 0.62 & $0.31-1.23$ & 0.17 & & & \\
\hline \multicolumn{8}{|c|}{ Cumulative CMS dose ${ }^{a, c}$} \\
\hline$<93.999 .975$ (IU) & $33 / 73(45)$ & 1.00 & & & & & \\
\hline$\geq 93.999 .975$ (IU) & $24 / 74(32)$ & 0.58 & $0.29-1.13$ & 0.11 & 0.61 & $0.29-1.29$ & 0.19 \\
\hline \multicolumn{8}{|c|}{ Duration of CMS therapy ${ }^{a}$} \\
\hline$<11$ days & $30 / 72(42)$ & 1.00 & & & & & \\
\hline$\geq 11$ days & 27/35 (36) & 0.78 & $0.4-1.53$ & 0.48 & & & \\
\hline
\end{tabular}

The variables included in the final predictive model were selected with a stepwise procedure: age and treatment with CMS were not included in the final model. ${ }^{a}$ age, SAPS II, duration of CMS therapy, and cumulative CMS dose were dichotomized around median values. ${ }^{b}$ The ROC curve analysis was used to assess the goodness of the final logistic regression model (AUC $\pm \mathrm{SE}=0.76 \pm 0.04$ with $95 \% \mathrm{Cl} 0.7$ to 0.8 ; Chi-square statistics $P<0.001$ ). ${ }^{C}$ Includes loading dose of $4,000,000$ IU. AKI, acute kidney injury; AUC, area under the curve; Cl, confidence interval; CMS, colistin methanesulfate; IBW, ideal body weight; IU, international unit; NAs, nephrotoxic antibiotics (aminoglycosides, glycopeptides); ROC, receiver operating characteristic; SAPS II, Simplified Acute Physiology Score II (calculated 24 h after ICU admission).

Table 6 Logistic regression analysis of factors associated with AKI in patients who received CMS and NAs

\begin{tabular}{|c|c|c|c|c|c|c|c|}
\hline \multirow[b]{2}{*}{ Variables } & \multirow[b]{2}{*}{ No. AKI/total (\%) } & \multicolumn{3}{|c|}{ Univariate analysis } & \multicolumn{3}{|c|}{ Multivariate analysis ${ }^{\mathbf{b}}$} \\
\hline & & O.R. & 95\% C.I. & $P$-value & O.R. & 95\% C.I. & $P$-value \\
\hline \multicolumn{8}{|c|}{ Age, years ${ }^{a}$} \\
\hline$<64$ & $36 / 110$ (32) & 1.00 & & & & & \\
\hline$\geq 64$ & $49 / 112(43)$ & 1.59 & $0.92-2.75$ & 0.09 & & & \\
\hline \multicolumn{8}{|l|}{ Sex } \\
\hline Male & $63 / 150(42)$ & 1.00 & & & & & \\
\hline Female & 22/72 (30) & 0.6 & $0.33-1.1$ & 0.1 & 0.6 & $0.29-1.2$ & 0.15 \\
\hline \multicolumn{8}{|l|}{ SAPS II ${ }^{a}$} \\
\hline$<44$ & 25/109 (22) & 1.00 & & & & & \\
\hline$\geq 44$ & $60 / 113(53)$ & 3.8 & $2.13-6.79$ & $<0.01$ & 2.45 & $1.17-4.74$ & $<0.01$ \\
\hline \multicolumn{8}{|c|}{ Septic shock at Infection onset } \\
\hline No & $19 / 121(15)$ & 1.00 & & & & & \\
\hline Yes & $66 / 101(65)$ & 10.12 & $5.34-19.12$ & $<0.01$ & 8.24 & $4.26-15.93$ & $<0.01$ \\
\hline \multicolumn{8}{|c|}{ Treatment with CMS } \\
\hline No & $54 / 132(41)$ & 1.00 & & & & & \\
\hline Yes & $31 / 90$ (34) & 0.75 & $0.43-1.32$ & 0.33 & & & \\
\hline
\end{tabular}

The variables included in the final predictive model were selected with a stepwise procedure: age was not included in the final model.

${ }^{a}$ Age, SAPS II were dichotomized around median values.

${ }^{b}$ The ROC curve analysis was used to assess the goodness of the final logistic regression model (AUC $=0.8 \pm 0.03$ with 0.75 to $0.8695 \%$ Cl; Chi-square statistics: $P<0.01$ ) AKI, acute kidney injury; AUC, area under the curve; $\mathrm{Cl}$, confidence interval; CMS, colistin methanesulfate; NAs, nephrotoxic antibiotics (aminoglycosides, glycopeptides); ROC, receiver operating characteristic; SAPS II, Simplified Acute Physiology Score Two (calculated $24 \mathrm{~h}$ after ICU admission). 
(including Acinetobacter baumanii, Pseudomonas aeruginosa and Klebsiella pneumonia), many authors have investigated its adverse effects, in particular, its potential nephrotoxicity. Like aminoglycosides, the polymyxins cause damage to the kidneys at the level of the proximal tubules, where both classes of drugs are extensively reabsorbed via the endocytic receptor protein megalin [18]. Colistin was originally used in the 1960 s to combat infections caused by gram-negative bacteria, but it was abandoned in the 1970s because of its reported association with high nephrotoxicity rates $[13,19]$ and because new, apparently less toxic antibiotics (for example, the aminoglycosides) were becoming available. Several studies published over the past decade, however, have demonstrated that CMS is not associated with serious adverse effects, and although nephrotoxicity incidence rates varied (0\% to $32 \%$ ) [20-24], they were clearly lower than those reported in the 1960s and 1970s. The differences between older and more recent findings have been attributed to various factors, including the increased presence of chemical impurities in older colistin preparations, the variable definitions of acute renal impairment used in the various studies, closer monitoring and, last but not least, the improved maintenance of patient hydration by today's physicians [20].

Research endorsed by the Acute Dialysis Quality Initiative led to the publication of the RIFLE classification, with standardized criteria for various degrees of renal dysfunction [6]. The RIFLE approach can detect AKI with high sensitivity and high specificity. It can also be used to predict the prognosis of affected patients, and it provides a useful framework for comparing the results of different studies. Two recent studies that used the RIFLE criteria to investigate colistin-related nephrotoxicity $[25,26]$ documented high incidences of mild renal impairment (about 43\%) in both cohorts (even though the two populations differed in terms of illness severity).

Indeed, in most recent studies, the colistin-treated populations have been heterogeneous in terms of baseline illness severity, baseline renal function and treatment variables, including daily doses and duration of treatment. Daily doses of CMS used in these studies ranged from 3 million to 11 million IU [21,25,27-30]. To make matters worse, there is also wide variation involving the type of preparation used, that is, CMS (where 2 million IUs correspond to $160 \mathrm{mg}$ of the drug) versus colistin base (where 2 million IUs equals $60 \mathrm{mg}$ ). The importance of universal dosing terminology has been emphasized by several investigators $[19,20]$.

This antibiotic is being used with increasing frequency to treat critically ill patients - despite the absence of clinical guidelines and dosing recommendations for this particular population. Multi-organ dysfunction and severe XDR infections can alter the pharmacokinetics of CMS and colistin in terms of half-life and rates of formation of colistin from CMS [30], and the larger volumes of distribution present in these critically ill septic patients can cause a lower concentration of the antibiotic [5]. Early and appropriate goal-directed fluid therapy is fundamental in acute resuscitation of these critically ill patients; however, it is almost always associated with a certain degree of fluid overload, especially in septic patients, which promotes tissue edema that could potentially contribute, itself, to progressive organ dysfunction. Both fluid balance and urine volume are independent predictors of mortality in adult critically ill patients with AKI [31].

Plachouras et al. [12] studied the pharmacokinetics of intravenously administered CMS in critically ill patients and concluded that a loading dose of at least 9 million IU of CMS is needed in these cases to produce plasma concentrations of the drug within the minimum inhibitory concentration (MIC) range indicative of susceptibility. Failure to achieve such concentrations can lead to the emergence of resistant strains, and it can also result in increased mortality.

In light of these findings, we decided to investigate the nephrotoxicity of high-dose CMS therapy, in terms of RIFLE-defined AKI, in patients with no AKI at baseline. Hartzell and collaborators [25] used a similar approach in a young and otherwise healthy population of patients on a general medicine ward. The patients had no other confounding comorbidity, but the mean duration of CMS therapy was longer than it was in our study. The authors found a significant association between the cumulative CMS dose and the risk of nephrotoxicity in patients receiving CMS for more than 14 days. This finding contrasts with the results of our logistic regression analysis, which showed that neither the cumulative CMS dose nor the duration of treatment was a risk factor for developing new-onset AKI in severely ill ICU patients. The median days of CMS treatment of our patients, however, was lower that than reported by Hartzell and collaborators and could probably justify the discordance with our results as well as the difference in severity of the two population studied. We agree, nevertheless, that creatinine levels need to be closely monitored in patients receiving prolonged treatment with CMS.

Pogue et al. [26] reported that CMS nephrotoxicity is related to the daily dose but not to cumulative exposure. However, the population they studied was heterogeneous in terms of pre-treatment renal function. Furthermore, although illness severity scores were not reported, their patients were probably not as critically ill as ours. Only $14 \%$ had septic shock, $15 \%$ were on vasopressors and only $62 \%$ were being mechanically ventilated. These 
are important differences because, as noted above, the pharmacokinetics of CMS and colistin are different in the critically ill $[5,29]$, and in our study a SAPS II score $\geq 43$ was independently associated with AKI. Comparison of findings in ICU and non-ICU cohorts is also complicated by the fact that the former patients are likely to be more closely monitored and more rapidly treated than those being cared for on general wards.

Septic shock was the strongest predictor of AKI in our cohort. Many authors agree that the renal effects of sepsis, per se, should not be underestimated. Early AKI is common in septic shock [32], and it may potentiate the effects of colistin and other drugs on the kidney. The combination of septic shock and AKI had a consistently negative effect on survival. Among the patients with septic shock who did not receive CMS at all (that is, those who were treated with NAs alone), the incidence of AKI was 64\% (45/70), which confirms the predominant role of septic shock in the kidney injury (Figure 1).

\section{Limitation of the study}

The main limitation of our study is its retrospective design. This shortcoming is partially compensated for by the large number of patients studied, but it is almost impossible to avoid. A prospective randomized trial would inevitably be associated with ethical problems since for many infections, colistin is the only treatment option.

None of the patients received the CMS as empirical therapy and a definitive appropriate therapy was achieved within 36/48 hours. There are no data showing that using CMS as an empiric regimen could reduce the risk of inappropriate therapy and/or could reduce the incidence of septic shock or increase the risk of AKI. These interesting issues should be tested by specific trials.

\section{Conclusions}

In conclusion, in ICU patients with normal baseline renal function who receive CMS and/or NAs, the incidence of AKI as defined by the RIFLE classification is clearly high - $40 \%$. However, high-dose CMS therapy does not appear to be a risk factor for this outcome. Instead, the development of AKI was strongly correlated with the presence of septic shock and with the severity of the patients' underlying illness, as reflected by the SAPS II score. These findings suggest that renal protection measures, such as blood volume maintenance, are of utmost importance in critically ill patients with infections that require treatment with CMS.

\section{Key messages}

- The incidence of AKI in critically ill patients without pre-existing renal diseases is strongly correlated with the presence of septic shock and with illness severity.
- Compared with other nephrotoxic antimicrobials, high-dose CMS does not appear to increase the risk of new-onset AKI in this setting.

\section{Abbreviations}

ACEl: angiotensin converter enzyme inhibitor; ADQI: Acute Dialysis Quality Initiative; AKI: acute kidney injury; BSI: bloodstream infection; CMS: colistin methanesulfonate; CICr: creatinine clearance; CRBSIs: catheter-related bloodstream infections; CRRT: continuous renal replacement therapy; CSS: steady state concentration; IBW: ideal body weight; ICU: intensive care unit; IQR: interquartile ranges; IU: international units; i.v.: intravenous; GFR: glomerular filtration rate; MDRD: Modification of Diet in the Renal Disease; MIC: minimum inhibitory concentration; NAs: nephrotoxic antimicrobials; NSAID: nonsteroidal anti-inflammation drug; ORs: odds ratios; RIFLE: Risk Injury-Failure-Loss-End-stage kidney disease; ROC: receiver operating characteristic; SAPS II: Simplified Acute Physiology Score II; Scr: serum creatinine; VAP: ventilator associated pneumonia; XDR: extensively drugresistant

\section{Competing interests}

The authors have no competing interests to declare relative to this article.

\section{Authors' contributions}

$M R, L M, E A, M V, P P$ and MA designed the study. AL, MV, GR and GDP collected and assembled the data. LM and EA performed the statistical analysis. MR, LM, MA, EA, PP and AL drafted the manuscript, and all authors have read and approved the final manuscript.

\section{Acknowledgements}

The authors thank Dr. Alessandra Giordano for her scientific support. Marian Everett Kent received payment from the authors for editing portions of the manuscript.

\section{Authors' details}

${ }^{1}$ Anesthesiology and Intensive Care, Sapienza University of Rome, Viale del Policlinico 155, 00161 Rome, Italy. ${ }^{2}$ Anesthesiology and Intensive Care, Catholic University of the Sacred Heart, Largo Agostino Gemelli 8, 00168 Rome, Italy. ${ }^{3}$ Department of Public Health Sciences and Infectious Diseases, Sapienza University of Rome, Viale del Policlinico 155, 00161 Rome, Italy.

Received: 6 December 2012 Revised: 6 February 2012 Accepted: 14 August 2013 Published: 14 August 2013

\section{References}

1. Talbot GH, Bradley J, Edwards JE Jr, Gilbert D, Scheld M, Bartlett JG: Antimicrobial Availability Task Force of the Infectious Diseases Society of America. Bad bugs need drugs: an update on the development pipeline from the Antimicrobial Availability Task Force of the Infectious Diseases Society of America. Clin Infect Dis 2006, 42:657-668.

2. Li J, Nation RL, Milne R, Turnindge J, Coulthard K: Evaluation of colistin as an agent against multi-resistant Gram-negative bacteria. Int J Antimicrob Agents 2005, 25:11-25.

3. Linden PK, Paterson DL: Parenteral and inhaled colistin for the treatment of ventilator-associated pneumonia. Clin Infect Dis 2006, 43(Suppl 2): S89-94.

4. Li J, Rayner CR, Nation RL, Deans A, Boots R, Widdecombe N, Douglas A, Lipman J: Pharmacokinetics of colistin methanesulfonate and colistin in a critically ill patient receiving continuous venovenous hemodiafiltration. Antimicrob Agent Chemother 2005, 49:4814-4815.

5. Markou N, Markantonis SL, Dimitrakis E, Panidis D, Boutzouka E, Karatzas S, Rafailidis P, Apostolakos H, Baltopoulos P: Colistin serum concentrations after intravenous administration in critically ill patients with serious multidrug-resistant, gram-negative bacilli infections: a prospective, open label, uncontrolled study. Clin Ther 2008, 30:143-151.

6. Bellomo R, Ronco C, Kellum JA, Mehta RL, Palevsky P, the Acute Dialysis Quality Initiative workgroup: Acute renal failure - definition, outcome measures, animal models, fluid therapy and information technology needs: the Second International Consensus Conference of the Acute Dialysis Quality Initiative (ADQI) Group. Crit Care 2004, 8:R204-R212. 
7. Magiorakos AP, Srinivasan A, Carey RB, Carmeli Y, Falagas ME, Giske CG, Harbarth S, Hindler JF, Kahlmeter G, Olsson-Liljequist B, Paterson DL, Rice LB, Stelling I Struelens MJ, Vatopoulos A, Weber JT, Monnet DL: Multidrug-resistant, extensively drug-resistant and pandrug-resistant bacteria: an international expert proposal for interim standard definitions for acquired resistance. Clin Microbiol Infect 2012, 18:268-281.

8. Garzotto F, Piccinni P, Cruz D, Gramaticopolo S, Dal Santo M, Aneloni G, Kim JC, Rocco M, Alessandri E, Giunta F, Michetti V, lannuzzi M, Belluomo Anello C, Brienza N, Carlini M, Pelaia P, Gabbanelli V, Ronco C, NEFROINT investigation group: RIFLE-based data collection/management system applied to a prospective cohort multicenter Italian study on the epidemiology of acute Kidney injury in the intensive care unit. Blood Purif 2011, 31:159-171.

9. Russell JA, Walley KR, Singer J, Gordon AC, Hebert PC, Cooper DJ, Holmes CL, Mehta S, Granton JT, Storms MM, Cook DJ, Presnell JJ, Ayers D, VASST Investigators: Vasopressin versus norepinephrine infusion in patients with septic shock. N Engl J Med 2008, 358:877-887.

10. American Thoracic Society, Infectious Diseases Society of America: Guidelines for the management of adults with Hospital acquired, ventilator-associated, and Healthcare-associated pneumonia. Am J Respir Crit Care Med 2005, 171:388-416.

11. Dodek P, Keenan S, Cook D, Heyland D, Jacka M, Hand L, Muscedere J, Foster D, Mehta N, Hall R, Bruin Buisson C, Canadian Critical Care Trials Group, Canadian Critical Care Society: Evidence-based clinical practice guidelines for the prevention of ventilator-associated pneumonia. Ann Intern Med 2004, 141:305-313.

12. Plachouras D, Karvanen M, Friberg LE, Papadomichelakis E, Antoniadou A Tsangaris I, Karaiskos I, Poulakou G, Kontopidou F, Armaganidis A, Cars O, Giamarellou H: Population pharmacokinetic analysis of colistin methanesulfonate and colistin after intravenous administration in critically ill patients with infections caused by gram negative bacteria. Antimicrob Agents Chemother 2009, 53:3430-3436.

13. Li J, Nation RL, Turnidge JD, Milne RW, Coulthard K, Rayner CR, Paterson DL: Colistin: the re-emerging antibiotic for multidrug-resistant Gramnegative bacterial infections. Lancet Infect Dis 2006, 6:589-601.

14. Pea F, Viale P. Pavan F, Furlanut M: Pharmacokinetic considerations for antimicrobial therapy in patients receiving renal replacement therapy. Clin Pharmacokinet 2007, 46:997-1008.

15. Pea F, Furlanut M, Negri C, Pavan F, Crapis M, Cristini F, Viale PG: Prospectively validated dosing nomograms for maximizing the pharmacodynamics of vancomycin administered by continuous infusion in critically ill patients. Antimicrob Agents Chemother 2009, 53:1863-1867.

16. Prins JM, Weverling GJ, de Blok K, van Ketel RJ, Speelman P: Validation and nephrotoxicity of a simplified once-daily aminoglycoside dosing schedule and guidelines for monitoring therapy. Antimicrob Agents Chemother 1996, 40:2494-2499.

17. Florescu DF, Qiu F, McCartan MA, Mindru C, Fey PD, Kalil AC: What is the efficacy and safety of colistin for the treatment of ventilator-associated pneumonia? A systematic review and meta-regression. Clin Infect Dis 2012, 54:670-680.

18. Vaara M, Fox J, Loidl G, Siikanen O, Apajalahti J, Hansen F, FrimodtMoeller N, Nagai J, Takano M, Vaara T: Novel polymyxin derivatives carrying only three positive charges are effective antibacterial agents. Antimicrob Agents Chemother 2008, 52:3229-3236.

19. Lim LM, Ly N, Anderson D, Yang JC, Macander L, Jarkowski A III, Forrest A, Bulitta JB, Tsuji BT: Resurgence of colistin: a review of resistance, toxicity, pharmacodynamics, and dosing. Pharmacotherapy 2010, 30:1279-1291.

20. Falagas ME, Kasiakou SK: Toxicity of polymyxins: a systematic review of the evidence from old and recent studies. Crit Care 2006, 10:R27.

21. Cheng CY, Sheng WH, Wang JT, Chen YC, Chang SC: Safety and efficacy of intravenous colistin (colistin methanesulphonate) for severe multidrug resistant Gram-negative bacterial infections. Int J Antimicrob Agents 2010, 35:297-300.

22. Kasiakou SK, Michalopulos A, Soteriades ES, Samonis G, Sermaides GJ, Falagas ME: Combination therapy with intravenous colistin for management of infections due to multidrug-resistant gram-negative bacteria in patients without cystic fibrosis. Antimicrob Agents Chemother 2005, 49:3136-3146.

23. Falagas ME, Rizos M, Bliziotis IA, Rellos K, Kasiakou SK, Michalopoulos A: Toxicity after prolonged (more than four weeks) administration of intravenous colistin. BMC Infect Dis 2005, 5:1.
24. Kim J, Lee K-H, Yoo S, Pai H: Clinical characteristics and risk factors of colistin-induced nephrotoxicity. Int J Antimicrob Agents 2009, 34:434-438,

25. Hartzell JD, Neff R, Ake R, Howard R, Olson S, Paolino K, Vishneopolsky M, Weintrob A, Wortmann G: Nephrotoxicity associated with intravenous colistin (colistimethate sodium) treatment at a tertiary care medical center. Clin Infect Dis 2009, 48:1724-1728.

26. Pogue JM, Lee J, Marchaim D, Yee V, Zhao JJ, Chopra T, Lephart P, Kaye KS: Incidence of and Risk factors for colistin-associated nephrotoxicity in a large academic health system. Clin Infect Dis 2011, 53:879-884.

27. Rattanaumpawan $P$, Ungprasert $P$, Thamlikitkul V: Risk factors for colistinassociated nephrotoxicity. J Infect 2011, 62:187-190.

28. Deryke CA, Crawford AJ, Uddin N, Wallace MR: Colistin dosing and nephrotoxicity in a large community teaching hospital. Antimicrob Agents Chemother 2010, 54:4503-4505.

29. Sabuda DM, Laupland K, Pitout J, Dalton B, Rabin H, Louie T, Conly J: Utilization of colistin for treatment of multidrug-resistant Pseudomonas aeruginosa. Can J Infect Dis Med Microbiol 2008, 19:413-418.

30. Nation R, Li J: Colistin in the 21th century. Curr Opin Infect Dis 2009, 22:535-543.

31. Teixeira C, Garzotto F, Piccinni P, Brienza N, lannuzzi M, Gramaticopolo S, Forfori F, Pelaia P, Rocco M, Ronco C, Anello CB, Bove T, Carlini M, Michetti V, Pelaia P. Cruz DN, for the NEFROlogiae Cura INTensiva (NEFROINT) investigators: Fluid balance and urine volume are independent predictors of mortality in acute kidney injury. Crit Care 2013, 17:R14.

32. Bagshaw SM, Lapisky S, Dial A Arabi Y, Dodek P, Wood G, Ellis P, Guzman J, Marshall J, Parrillo JE, Skrobik Y, Kumar A, Cooperative Antimicrobial Therapy of Septic Shock (CATSS) Database Research Group: Acute kidney injury in septic shock: clinical outcomes and impact of duration of hypotension prior to initiation of antimicrobial therapy. Intensive Care Med 2009, 35:871-878.

\section{doi:10.1186/cc12853}

Cite this article as: Rocco et al.: Risk factors for acute kidney injury in critically ill patients receiving high intravenous doses of colistin methanesulfonate and/or other nephrotoxic antibiotics: a retrospective cohort study. Critical Care 2013 17:R174.

\section{Submit your next manuscript to BioMed Central and take full advantage of:}

- Convenient online submission

- Thorough peer review

- No space constraints or color figure charges

- Immediate publication on acceptance

- Inclusion in PubMed, CAS, Scopus and Google Scholar

- Research which is freely available for redistribution

Submit your manuscript at www biomedcentral com/submit
C Biomed Central 